\title{
The Strategy Of Developing New Products: A Requisite For The Development And Survival Of The Businesses
}

\author{
Ioanna Dimitrakaki
}

\begin{abstract}
This article refers to the procedure of producing new products. In an era in which financial crisis has limited the available resources of businesses it is especially useful for the business to produce products which will be able to support it in its goal to maintain its market share. In this project, the case of the Ohonos Snack S. A. Company was examined. This company belongs to the field of snacks and it mainly operates in Northern Greece and the Balkans.
\end{abstract}

Having used the selected research method -Panizzolo, Biazzo, and Garengo model- the ways of improving production and the assurance of the suitable conditions for introducing a product in the market were presented.

The research, which was conducted through interviews, showed that the procedures mentioned in the bibliography are followed to a great degree. This means that the suggestions to the company are mainly related to its being able to have a both economical and efficient process.

The goal of this research is to investigate the strategy of developing new products and if it contributes to the development of the businesses' competition and their survival in the presentday hard competitive market.

The conclusions drawn showed that the introduction of new products has proved to be a powerful tool of strategy the industry has in order to maintain a large market share.

Keywords-models of development; new product; new product efficacy; strategy of development

\section{INTRODUCTION 1}

It is known that globalization and freedom of market have increased competition among companies. In this way, companies get involved in a series of continuous changes and in the research of innovations which will make them be in a better condition than their competitors. A basic factor which contributes to the success of a company is the development of more and more successful products.

The decision of the development of new products (New Products Development - NPD) by a company is one of the most significant decisions in its function. The introduction of new products in the market is a powerful tool of strategy so that it can gain or maintain an important market share.

It is obvious that the development of new, innovative products or services does not content itself with the conception of an idea or discover or with the improved version of an existing product. It is a complicated process

Published on January 24, 2020.

(e-mail: iondimi@hotmail.com) whose scopes and responsibilities must be combined and completed in such a way so that its successful introduction in the market is allowed. The program of the development of new products needs to be frequently adapted in order to mirror the changes in the competing environment and technology.

The combinatorial aspect of the development of a new product for the transformation of the most suitable idea into an investment does not always guarantee the success of a new product. Good ideas do not mean serviceable, attractive products, as a matter of course. A practical aspect which will successfully perform the conception of an idea has to be added to it. The aim of all these is that consumers are able to select an alternative innovative product for which they will be amenable to pay the corresponding price since it will be able to satisfy their needs.

Thus, a business produces a real product presuming on researches regarding the consumers' preferences hoping that it will meet the ideal product consumers have in their minds.

\section{A. Importance of the subject}

Businesses must be able to develop new products and services in order to handle the increase of competition as a result of financial misery in the markets. Businesses have to be able to continuously search new markets so that they discover new parts of the market and changes in the profile and behavior of clients to develop new products or services which will conform to those changes [1]. The success of the development of a new product is also due to the preexistence of ideas which originate either from internal or external sources.

\section{B. Aim of the research}

The aim of the research in this article is:

1. To investigate the appropriateness of the strategy of New Products Development to support the survival and development of a business.

2. To find methods which businesses have used for the development of their products from time to time.

3. To define models of New Product Development Practices and their existence role in a business.

4. To describe the procedure of products development which is one of the basic success ingredients of a business. 
5. To find the changes which the application of the procedure of New Products Development will cause.

More specifically, what was measured was the need and the reasons of the development of a new product, the ways of development of new products and mainly the degree of effectiveness for the further development, survival, and profitability of a business.

\section{Goals of the research}

The goals of this research are the following:

1. To collect information from the literature review as to the relationship between consumers' behavior and the strategy of development of a new product.

2. To select the suitable theoretical model of strategy of development of a new product.

3. To provide a real image regarding the current situation of snack foods industries and the possibility of launching a new product.

4. To select, through primary research, the appropriate methods of assessing new ideas for the development of a new product and the degree of dependence of the business survival on this strategy.

5. To conduct an analysis of the research results, draw conclusions, and make suggestions.

\section{A brief account of the research methodology}

The research that was conducted for the needs of this article aims at examining all those elements which will help so that the strategy of development of new products is suggested to the company Ohonos Snack S. A. after the analysis of the research results.

Two researches were conducted to achieve the goals of this project:

1. The secondary research which depended on the collection of elements from libraries, books, online sources, and elements of businesses.

2. The primary research which was conducted with a qualitative research through interviews so that elements regarding the strategy and the way of new products development the company where the research was conducted applies are drawn on.

\section{E. Reasons for selecting the subject} following:

The reasons for selecting the subject are the

1. To enrich the knowledge of the researchers in respect of strategies of development.
2. To assess the appropriateness of the development of new products to positively affect the survival of businesses.

3. To develop new products, mainly in new markets abroad; this is the solution to the current inactivity of Greek businesses because of the international adverse economic condition.

4. In that case, it is important that the researcher focus on the way in which a business will have more profits but also an advantage in comparison with its competitors, by developing new products.

5. Another reason to select this subject was that the researcher attempts to answer the main relative matters, such as: What is the development of a new product? Which is the reason of developing a new product? What does the development of a new product aim at? However, it is mainly the enrichment of the researcher's knowledge so that the necessary suggestions with regard to time, way, method, procedure, and reasons of success of developing a new product are made.

\section{F. Structure of the article}

The structure of this article includes six chapters in which the following are included:

In the first chapter, there is the introduction. In the second chapter, the theoretical framework with the most important theoretical approaches, the procedures of developing new products, the reasons of success of new products, the strategies of the development of new products, and the models of strategic development are cited and it finishes with the analysis of the theoretical model selected and the description of the field of the company Ohonos Snack S. A. and of the company itself. In the third chapter, the methodology of research and the steps followed for its conduction are presented. In the fourth chapter, the analysis of the elements of the research is cited. Finally, in the fifth chapter, the conclusions drawn from the analysis of data, as well as the making of corresponding suggestions are developed.

\section{LITERATURE REVIEW}

\section{A. Meaning and definition of "product"}

It is understandable that a product consists of many levels, either it is simple, such as a coffee cup, or composite, such as an industrial tool. Traditionally, a product was simply the result of a producing procedure [2]. A product can be defined as a totality of usefulness and mileage. That is why we now say that a product is not only a material, palpable object with physical characteristics, but a comprehensive conception in the consumer's mind which creates a commensurable expectation of satisfying his needs. According to marketing, a producer does not sell products anymore; he sells advantages that derive from products [3].

\section{B. Procedure of developing new products}

All businesses are created, act, and develop in a dynamic environment which continuously evolves. 
Businesses face the challenges of decreasing the amount of failure of the new products and services they develop and of increasing the lifetime of their products in order to increase their profits and to gain an advantage over their competitors [4]. Every business has its own standards for planning the procedures of New Products Development (NPD), according to its size, the kind and number of the products or services it produces, as well as the environment in which it operates, Therefore, other businesses focus more on improving quality and others do so on improving the technical standards of their products, whereas others search for procedures of developing new products which will decrease the time of development and accelerate the producing procedure. According to Bowen et al. [5], the development of new products is one of the fundamental procedures of a business and it is a basic source of revitalization and improvement of the competitive edge. The first research on the way of synthesizing a procedure of developing a new product and its impact on the efficiency of a business was conducted by Booz, Allen, and Hamilton in 1968 (in 50 businesses) and it was repeated in 1982 with a larger sample size. Strategy, as a basic factor of the NPD procedure, was added to the 1982 research. Businesses from North America participated in the research and it was established that $75 \%$ of the most successful ones traded according to a specific strategy.

Nelson and Winter [6] were among the first who realized that individuals with different abilities and qualifications should be organized and interact so that they can have a better effect in their everyday scopes. The results of the research conducted by Pittiglio Rabin, Todd, and MacGrath [7] were similar. It was found that the businesses which used cross-functional teams, applied various development "tools", such as emulations, and acted according a specific strategy and program applied the best NPD practices among the 200 high-tech businesses which took part in the research.

In 2004, Mercer Management Consulting, in collaboration with the R\&D Journal, collected elements from 193 businesses and, according to the results it came to the conclusion that there is a connection among the practices of developing new products and the efficiency of the NPD procedure, the lifetime of a product and the earnings of the business. Finally, in summer 2006, Southwestern Bell conducted research among 134 businesses. It resulted that $57 \%$ of the businesses applied a specific NPD procedure, whereas $52 \%$ of them considered consumer research as a basic element of the function of promoting new products [8].

The procedure practically begins with the unavoidable end of the product life cycle which is essentially what creates the need of constant development and introduction of new products in the market. According to the product life cycle, a product comes to life, gradually develops, maturates and reaches the end of its life when most consumers do not desire it any longer. That is when the first stage of developing a new product begins: the stage of Idea Generation. As for new products, we should note here that the stage which is first is the stage of developing a strategy of a new product which plays a most important role, although it is not a functional part of the process, because it associates the business strategy with the attempt to develop new products and it defines the role and place of them [9].

The stage that follows is that of the Idea Screening and Evaluation with three basic evaluation criteria: first, ideas should conform to the whole strategy of the business, second, ideas should "build on the sources of the business", and third, an idea should satisfy market so that it can enter the next stages. The stage of Business Analysis is next. Predictions pertaining at cost, profit, efficiency, sales, budget, and assessment of the risk are made for the few ideas that have survived until that stage. After that, the stage of Development in which an idea becomes a real product comes next. The departments of research and production undertake the project. The next stage is Testing where it is tested on a limited scale if a product meets the original standards and if it covers the needs for which it was developed, i. e., the attitude of consumers towards the product is researched. The stage of Commercialization follows where the product is introduced in the points of sale, on condition that a complete marketing plan has been developed and applied. This is the most costly stage, since a business allocates great amounts of money for the promotion of a new product.

After completing the process required so that a product can take its final form, a business should apply a strategy of pricing for its most efficient promotion in the market. Bergstein and Estelami [10] mention that the biggest challenge businesses face during launching a new product in present-day competitive market is the definition of its selling price. The acceptance of the selling price of a new product by consumers mainly depends on the unique qualities which will be provided by that product in comparison with every similar product which is available in the market.

\section{Models of strategy of developing new products}

There are many models of strategy of developing new products, yet three models will be mentioned for the needs of this research. More specifically, the first model we examine, that of Lee and Wong [11], appertains to the variables which allow the development of a successful product so that it can be successfully launched in the market. Variables concern a series of functions such as marketing, collaboration among departments, technology synergies which lead to a combination of marketing skills and modern technology so that a new product is produced. This model gives a special emphasis to what regards the interdepartmental relations and also the relation between managers and the other departments of the business so that a new product will be a fruit of collaboration between different departments.

The basic stages for a new strategy of developing a new product are analyzed by using the theory of Kotler [2].This model allows us to track the workflow of developing a new product so that it can be successfully introduced in the market and secure the livability of the business. Eight stages of this model are required for the successful and durable introduction of a product in the market. Those must be 
carefully applied and the right decisions must be made so that the danger of producing a product which will not meet the consumers' needs is decreased.

Afterwards, we examine the selection model of Panizzolo, Biazzo, and Garengo [12] which regards the way in which a process for developing a new product can have high standards. The process has to do with focusing on the market, production matters, and the procedure of quality testing.

Each one of the three variables consists of a series of factors which will affect the development of a new product. The first variable is emphasis on the market. In that case, the success factors are the following: the strategy of development, the planning of the product, the comprehension of the clients' needs, the definition of the qualities of the product, the commercialization plan of the new product, the designing of the product. As we can see, this variable concerns elements appertaining to the ability of a new product to meet the needs of the markets in which it is going to be introduced. The second variable is the production of the product. The elements which affect it are: the involvement of the production executives in planning, the costing, the notification of procurers and the exchange of views with them, the preparation of the production line, and the definition of technical standards. The factors that define the second variable are about the producing ability of the company. For this purpose, a cost which a business can bear is examined. The third variable is the quality testing. The factors of defining it are: constant improvement, leadership, methods of project management, definition of the team of quality testing, and automation of planning. The factors which pertain to the third variable refer to the quality testing. Many new products are frequently defective. For this reason, the quality of the production should be secured. The third model is the model of research as well. We have chosen this model because it can show us the ways of improving production and it also secures the suitable conditions for its introduction in the market.

\section{Profile of the company}

Ohonos Snack S. A. was established in 1994 and it is a Greek company with a high expertise in snacks and chips. It became an industry in 1997 and it has gained a large market share since then. Moreover, it was solidified in the international market, exporting $50 \%$ of its products. Highly qualified personnel are employed in its state-of-the-art premises, so that it can offer excellent quality products to the clients. The selected raw materials and packaging materials used for the production of the products qualify for all the legislative quality, hygiene, and safety standards, securing the excellent quality which consumers have been trusting for many years. The good manufacturing practice which is followed secures the high quality of the products and it has been certified by the standards ELOT EN ISO 9001:2000, ELOT 1416 (HACCP) since 2005 and ISO22000:2005 since 2009.

According to the company's balance sheet, sales amounted to $€ 12,000,000$ out of which $60 \%$ came from sales in the national market and $40 \%$ from sales abroad, mainly in Bulgaria, Romania, and other European countries.
The amount of sales in the national market amounts to $12-13 \%$ out of the total sales of salty snacks and chips.

The company's products are distributed by proprietary transporters from warehouses of merchandisers collaborating with Ohonos Snack S. A. to every Greek city, whereas the distribution network of the Ohonos Snack S. A. Company which consists of suitably educated sellers distributes directly the products in the administrative region of Attica and the regional unit of Thessaloniki. The products are distributed abroad through a distribution network of a collaborating allied industry of snacks and croissants with the company name Best Foods Prod which operates in Bulgaria and Romania.

\section{METHODOLOGY OF RESEARCH}

\section{A. Definition of the research goals}

The goal of this research is to investigate if the strategy of new products development in the case of Ohonos Snack S. A. can have a positive impact on the whole strategy of the business.

\section{B. Secondary research}

The secondary research depended on elements collected from libraries, sources, and data from the business itself to create the basis of the literature review.

\section{Primary research}

The primary research is divided into quantitative and qualitative. The quantitative research is based on the measures and, to a large extent, on the statistical analysis, so that the decisions which will be made are stable. It is mainly based on answering a questionnaire, whereas the qualitative research aims at helping the researcher in the investigation and interpretation of the parameters which define the multidimensional aspects of a certain behavior [13].

This project depended on the qualitative research through interviews with Ohonos Snack S. A. executives. The qualitative research was preferred because, according to Denzin and Linkoln [14], when a respondent has to face a new piece of knowledge which continuously evolves and has not been stabilized in its final form, it can be the most important method of approach.

The qualitative research allows the researcher to develop critical thinking regarding the subject of the research and to move freely, without the restrictions of the quantitative research.

On the contrary, the quantitative research can allow the researcher to select some kind of research in a large sample and to analyze the data statistically, but it does not mean knowing something new nor can it study the social transformations and evolution which happen in the subject of the research. According to McDaniel and Gates [15], the use of the qualitative research is the most favorite method of analyzing researches which are conducted within a business. 
For this reason, qualitative research was conducted through a semi-structured interview held through an interview guide whose questions were based on the parameters of the three variables of the Panizzolo et al. [12] model.

The data analysis from the interviews was based on the comparison of the views mentioned by the interviewees with those maintained by the Panizzolo et al. [12] model. Furthermore, in this project, the qualitative research was considered more suitable, since the executives decide, define the procedures, and realize the development of new products. More specifically, the research focused on abstracting data regarding the discovery of the most suitable strategy of developing new products, whereas, at the end, after the analysis and evaluation of the data, the conclusions and suggestions which arose from the research are presented.

\section{Goals of primary research}

The goals of primary research are the following:

1. To find if the basic characteristics and factors of the three variables of the Panizzolo et al. [12] model are applied in the Ohonos Snack S. A. Company.

2. To diagnose the factors related to the activities of the company, aiming at:

1. Giving emphasis to the market, by researching the strategy of development, the planning of a new product, its commercial design and designing

2. Producing the product, by researching the designing of a new product, the involvement of executives, the production, costing, notification of suppliers, and definition of the technical standards.

3. Testing the quality, by researching continuous improvement, methodology of project management, definition of the control group and automation of designing/planning.

\section{E. Qualitative research}

The most usual approach for collecting information regarding behavior, attitude, opinion, and characteristics is to ask directly about them [16].

The method which was followed was a face-to-face and in-depth semi-structured interview by using a recorder, in the offices of the company's managers. It was used as a sample of the qualitative research. The semi-structured interview is based on a strict total of predefined questions which are asked to all the respondents in the same way.

The sample of the four managers is: one member of the board of directors, the Production Manager, the Marketing manager, and the Sales Manager.

Afterwards, on the prearranged days, the researcher visited the managers in their offices where the view of each one were developed and recorded with a recorder. The time of conducting every interview was 20-30 minutes.
The reason that led to the preference of the interviews was that those individuals are highly knowledgeable about their fields, are able to express their views, make suggestions, and evaluate the elements and ideas according to the needs of developing new products.

\section{F. Steps before the interview}

A plan of questions regarding the subject at issue was created and it was divided into three units, the number of the variables of the model selected:

1. Emphasis on the market.

2. Production of the product

3. Quality testing

After that, the questions for each variable were created so that they cover all the factors which concern the variables.

\section{ANALYSIS OF DATA}

\section{A. Analysis of elements}

The analysis of the qualitative data was conducted according to the type of the typological analysis [17]. The qualitative material is structured in categories so that the issue they include is exhausted as much as possible, aiming at the clarification of possible differentials between the managers' opinions and those of the Panizzolo et al. [12] model so that suitable suggestions are made.

\section{B. Qualitative research}

At this point, the qualitative research that was conducted in the Ohonos Snack S. A. Company is presented. The data were collected through in-person interviews. The questions which the managers were invited to answer were eleven and they belong to three thematic fields. The interviews were performed from 20 to 23 April 2019.

\section{Codification of qualitative data}

1. Emphasis on the market

In this variable, according to the Panizzolo et al. [12] model, the factors of successfully developing a new product are examined. Those are related to the strategy of development, the designing, the understanding of the clients' needs, the commercial design and qualities of the new product so that it can meet the needs of the markets in which it is going to be introduced.

The goal of the development of the first variable is to find the strategic directions so that the factors related to the emphasis on the market are achieved.

The answers given to the questions appertaining to the emphasis on the market are presented below:

1. Which is the attitude of managers towards the development of new products? 
According to the factory manager, they believe that new products certainly play an important role to the development of their company. They often have to update their product range so that they can measure up to the new market trends. Moreover, the fact that their company has a share in foreign markets too means that they should continuously develop and adapt their product range to the consuming habits in those countries.

2. Which is the procedure followed by the company for the development of new products and which are the elements taken into consideration?

The manager of the marketing department mentioned that the designing of new products is a complex and complicated procedure. In any case, it begins from the finding of the need, the realization of the idea, and the pilottest in the market.

However, not only should the rules and the cost taken into consideration, but also -mainly- the preference of the consumers. For this reason, the procedure is always followed by pilot studies, so that they observe the reactions of consumers and do the corresponding changes. Afterwards, the manager of designing mentioned that they strongly focus on the designing of the product but also of its package with a view to achieving a nice appearance and the corresponding cost. According to the quality manager, this is the procedure since it has been certificated with the corresponding ISO. From the answers, it can be seen that the procedure follows what we saw in the literature review to a great degree. The company simply strongly emphasizes on the consumers' reaction and the testing of the procedures.

3. How can we secure that the new product will be successful?

During the interview, the member of the board of directors mentioned that nobody can guarantee the success of a new product. What can be done is testing the quality and conducting pilot studies so that they know which the reaction of the consumers might be.

4. Are the consumers' needs taken into consideration for the designing and production of a new product?

The answer of the sales manager was that this was already mentioned in previous questions. The consumers' needs are their overriding concern. When they design something new they take into consideration the current financial statement of the potential consumers regarding the purchase of a new product of their company.

Further to the previous answers, it seems that there is a customer-driven approach regarding the handling of the whole procedure. This is a result of the orientation of the business and the producing procedure to quality.

5. Does a market analysis precede the decision of developing a new product?

The answer of the manager of the marketing department was that it is necessary. Although they often have prepared studies by ICAP and elsewhere, as well as the experiences of their sellers who communicate with customers and consumers, a commensurable market analysis through either primary or secondary research so that the procedure which is a significant financial investment for them begins. This is necessary so that the procedure continues or is intercepted. After that, the sales manager mentioned that they test to a great degree not only what a market asks for but also whether they can give it what it asks for.

The answer shows that the company indeed strongly focuses on being able to make decisions according to brought up to date data from the market. It would be invalid to be mentioned that the business can proceed to such a procedure without having secured that there is a real need in the market. market)

Evaluation of the first variable (Emphasis on the

As it resulted from the interviews, the overriding concern of the management of the company is the stabilization or increase of the percentage of sales. For the achievement of this goal, the strategy of developing new products is strongly focused on so that the business has a competitive position in the market. From the words of the marketing department manager: "No one can guarantee the success of a new product" one can understand the degree of the effort made by company executives and mainly the marketing department so that the need of launching a new product in the market is realized, especially in the current financial conditions, when a mistake has a great economic impact on the results of the company. The market analysis before the development of a new product is necessary. It is the most important parameter which should be examined but this does not mean that the company can decide to develop a new product without taking into consideration the parameter of cost. After all is said and done, the factors examined for the strategy of developing a new product and the variable of emphasis on the market are important and they have to satisfy all those requirements so that the company decides the development of a new product. The sales manager added that the process also concerns the discovery of the best practices in the market aiming at the best production of the new product.

\section{Production of the product}

In this variable, the factors of a successful development of a new product which are related to the production of the product, the production capacity of the company, the involvement of the business executives into the designing, the costing, the views exchanging with the suppliers, the preparation of the production line, and the determination of the technical standards.

The goal of the development of the second variable is the examination of the suitable technical standards so that a new product which the company can afford is produced.

The answers given to the questions concerning the production of the product are presented further down: 
1. Is there any involvement of the employees and suppliers into the production process of a new product?

According to the production manager, there is an involvement -mainly of the employees- into the production process of a new product. They would not like the suppliers to know what the company is working on because information might easily transpire. If their opinion is necessary, this will be near the end of the process. On the contrary, they always ask the opinion of their employees and a special effort is made so that the business employees are always informed about and aware of the production process. This is achieved thanks to the frequent educational and edifying seminars organized by the company.

What can be seen from the answers is that, to a great degree, there is an acceptance of the view that employees play an active role in the procedure but it seems that the business hesitates to involve the suppliers in the procedure too.

\section{Which is the way of costing the project?}

It was mentioned by the manager that much attention is paid regarding the project costing. There is a collaborative effort among the financial department and the other ones which are in charge of the development of a new product. The preliminary estimate for developing the product is what is taken most into consideration regarding the final decision. The departments develop a detailed strategic plan so that the development cost is minimized and the amount of the necessary financial resources which are required for the completion of the project is determined. It must be noted that the price of the competitive products that are available in the market is also taken into consideration. Regarding that opinion, the quality manager mentioned that there are various techniques, such as ABC Costing, so that the business can cost the project.

It seems from the answer that the factor of cost critically contributes to the decision of developing a new product but also the corresponding techniques are applied.

3. Is any preparation process followed regarding the production of a new product?

The production manager mentioned in his answer that there are standards. Of course, in any case, they can change according to the product and to what is asked for. However, there are certainly some determinate standards and the corresponding production line which can change as long as the production of the product requires it. But they generally try to have specific standards so that there is an economy of scale.

It seems from the answers that there is a specific process so that there are economies of scale and determinate procedures. product)

Evaluation of the second variable (Production of the

As it resulted from the interviews, the overriding concern of the company and mainly of the production department is the examination of the suitable factors so that a product the business can afford is produced. From the words: "We try to have specific standards and an economy of scale" it seems that the production department does its best to produce a product so that it can achieve all the factors of the variable of the Panizzolo et al. [12] model at the least possible cost.

\section{Quality testing}

In this variable, the factors of successfully developing a new product regarding the continuous improvement, the methods of handling the project, the determination of the quality testing team, and the automation of designing are examined.

The goal of the development of the third variable is to secure the quality of the production of new products.

The answers given to the questions concerning the product testing are presented below:

1. How is the quality tested during the production of a new product?

The quality manager mentioned that the quality testing is conducted about every half hour in the laboratory with scientific, chemical, and microbiological analyses. The quality is tested during all the stages of the development process of the product. First, the raw material is tested in the chemical laboratory of the company. This is considered the most definitive test because the raw material determines the final characteristics of the product. After that, the product is tested during its production. This is a detailed test regarding all the characteristics of the product (color, taste, smell, etc.). Then, the test during packaging which contributes to the nice appearance and the right maintenance of the product follows.

It seems from the answer that there is a very strict quality testing, which is something positive, so that the quality of the final product is secured, given that the foods quality standards of the European Union have been very strict recently so that the foods production businesses are obliged to apply the systems of managing quality with great attention.

2. Does the company try to upgrade the quality testing department so that it automates the designing of a new product?

The member of the board of directors answered that they generally try to do so. However, the cost is great so they try to do necessary and not bedazzlement actions, given that competition is so hard that it forces them to be careful in all sectors that economically affect the development of a new product. Besides, the quality testing department of the company is most based on chemical tests where a suitable person is the determinant factor.

It seems from the answers that the steps taken are careful so that the company upgrades its quality testing only when this will be necessary. 
3. How is the quality of a new product tested during its placement at the points of sale?

The marketing manager answered that the test is conducted, to a great extent, by the sellers, who know that the basic goal of the placement is to answer why consumers should purchase the product and how, when, and where it should be placed because the success of a product in the market depends on its differentiation and the elevation of a unique characteristic which is given prominence to during the placement.

Thus, it seems from the answer that the sales department contributes to the testing at the points of sale. This is achieved through the daily visits of the sellers to all the points of sale so that they are informed about the course of the new product, mainly during its placement.

\section{Evaluation of the third variable (Quality testing)}

As it resulted from the interview, the quality testing of a new product and the assurance of the quality of production are factors to which the company pays great attention. According to the "continuous improvement" factor, the conduction of tests during every stage of the producing procedure is strict so that the goal of producing excellent products and avoiding the phenomenon of faulty ones is achieved.

\section{CONCLUSIONS AND SUGGESTIONS}

\section{A. Conclusions of the quality research}

The conclusion that the need for new products is continuous is drawn from the analysis preceded. The introduction of new products has proved to be a powerful strategic tool in the hands of an industry so that they maintain an important share in the market. This article analyzed matters concerning an internal process of marketing which people cannot often follow but it is very important since what is most significant for the company is to be able to maintain their market presence thanks to the production of new products and the upgrade of the existing range of products.

The research conducted in the Ohonos Snack S. A. Company showed how much the right handling of the product marketing and more especially of the process of producing new products can help a business to achieve its goals.

Furthermore, the research showed that the development of new products is a process with a special risk in all its forms. Regarding the industry risk, the company strongly focuses on its ability to transform the original idea into a new product. As for the market risk, the company tries to investigate the market trends and whether something new can cope with competition before it decides to develop a new product so that the market accepts it. And finally there is the technology risk where the company thinks whether the technology is new and it is immediately assimilated. Taking into consideration the current situation, it is logical for the businesses to be particularly careful regarding the way the producing process of a new product is going to be realized.

The elements the Ohonos Snack S. A. Company takes seriously into consideration are the following:

1. The reception of the consumers

2. The ability of raising the commensurable funds

3. The quality tests and the consumer research

It is obvious from the interviews conducted that the business is especially careful in its choices with reference to the production of new products. We observed that the opinion of people regarding goods is very important. That means that the business should produce goods according to the special choices of its consumers. For this reason, there is the consumer research, as well as the pilot tests of the product so that its adequate function is secured.

Another parameter mentioned is the fact that the requirements which concern the quality and safety of products are satisfied to a large extent. The Ohonos Snack S. A. Company has been certificated with the corresponding ISO and HACCP but they also emphasize the interior spaces, apart from what the certifications ask for, so that the business is certain about the final result of the tests. We ought not to forget that foods production is a special process to a great degree and businesses should be particularly careful concerning the foods since health is an important issue and it would be unpleasant if the company produced products which would be harmful to health.

In comparison with the Panizzolo et al. [12] model, the following conclusions are drawn:

1. Emphasis on the market: The research shows that the business has really placed emphasis on developing new products according to the needs of the market. That means that the corresponding consumer research should be conducted before the procedure of producing a new product starts so that both the needs of the market and the ability of the product to satisfy them are investigated. Moreover, the business conducts pilot studies based on the original product so that it can examine if the market is finally positive towards it.

2. Production of the product: The business is based on a stable production line. The new products should be able to be adapted to the production line and the particularities of the company so that it can have economies of scale and be competitive in the market.

3. Quality testing: The business has been certificated with all the corresponding ISO and HACCP. In addition, it has managed to have an autonomous department of quality testing. Thus, it can test itself the standards of whatever new product is going to be available and of whatever is adapted to the needs of the market. Management also plays an important role and the suitable techniques of project management are used.

\section{B. Suggestions}


Having finished the analysis of the results of the research in the Ohonos Snack S. A. Company, we can make some suggestions so that the company continues to develop new products which will be competitive in the hard economic conditions which prevail.

Regarding the emphasis on the market, the following are suggested:

1. The business should be continuously open-eyed so that it can understand the needs of the customers to a large extent because consuming behavior is formed according to every consumer's purchasing power because of the economic crisis. That means that the business should always develop and promote products which will satisfy consumers at the lowest possible cost.

2. Consumer researches to find the needs should be conducted. There ought to be ad hoc researches to a specific sample of consumers. The goal of the business is to be able to observe the changes in their attitude towards its products as well as their general reaction to new stimuli.

3. Focus groups for brainstorming should be created so that the business can decide how it will continue the project and how the conception will be designed according to the customers' preferences.

4. Regarding the competitive power of a company in comparison with other ones, a detailed analysis of the potentials, inadequacies, and expectations of launching a new product. It should use every possible information wherever it comes from so that it can understand the way the competitor managed to have either a large or a small market share.

Regarding the production of the product the following are suggested:

1. The business should always be informed about the purchase of raw materials, an element which determines the costing of a new product. This can be achieved by the continuous information by the suppliers and mainly by the collection of information concerning the forthcoming increase of the raw materials cost mainly at the external market. The company should also minimize the producing cost with the right actions which should be applied to the production line too, that is, the installation of faster producing and packaging machines and the education of the production personnel through seminars concerning teamwork.

2. Consumer researches should be conducted in different phases of the producing process aiming at the evaluation of the characteristics, e. g. taste, crispness, dietary value, and acceptance of package.

3. Regarding the third factor of the second variable of Panizzolo et al. [12] which is the notification of the suppliers and the exchange of view with them, it is suggested that the company put great emphasis on the discussions with the distributors and the consumers but mainly the owners of the points of sale, about the distinguishing feature of the new product which is what matters for the consumer. Besides, this is the core of marketing itself.

4. The relations of the business with its employees should be orderly because, in case of poor labor relations, there might be a negative impact on the quality of a new product and on the time of placing it, an important fact in case the company wants to have a competitive edge. suggested:

Regarding the quality testing the following are

1. There should be a systematic automation of designing new products by the constitution of a team consisting of employees with high specialization in designing new products. This team should be advisory and it should act in collaboration with the quality testing department. Thus, the cases of producing a faulty product are minimized and the quality of both the production and the product will be secured thanks to teamwork.

2. Due to the particularity of the products of the company (continuous alternation of raw materials on the production line), it is suggested that machine operators, who should be trained in control methods, but mainly they should be responsible concerning the quality of the products, conduct detailed controls.

\section{Conclusion}

Modern marketing wants businesses to be able to be adapted to the consumers' needs. For this reason, this article analyzed the case of the development of new products process and, more specifically, that of the Ohonos Snack S. A. Company.

This project was based on the analysis of the related bibliography and then it presented a series of models regarding the development of new products. The Panizzolo et al. [12] model was selected as the most effective of the models presented and the quality research was conducted according to that.

The research was conducted through four interviews with executives of the Ohonos Snack S. A. Company. The results show that the business lays great emphasis on the production of new products and this can secure its sustainability in the future.

\section{REFERENCES}

[1] V. Wong, "Antecedents of international new product rollout timeliness," International Marketing Review, vol. 19, no. 2, pp. 120-132, 2002 . 
[2] P. Kotler, Marketing Management, Harlow: Pearson, 2009, p. 614.

[3] D. Meyersdorf and D. Dori, "System modeling of the R\&D domain through the object - process methodology: a practical tool to help R\&D satisfy its customers' needs," R\&D Management, vol. 27, no. 4, pp. 333344, 1997.

[4] J. M. Bonner, R. W. Ruekert, and O. C. Jr. Walker, "Upper management control of new product development projects and project performance," Journal of Product Innovation Management, vol. 19, no. 3, pp. 233-245, 2002.

[5] Bowen et al., Copeia, pp. 34-41, 1994.

[6] R. R. Nelson and S. G. Winter, An evolutionary theory of economic change, Cambridge MA: Belknap Press of Harvard University Press, 1982 .

[7] Pittiglio, Rabin, Todd, and MacGrath, Product Development Leadeship for Technology-Based Companies: Measurement and Management- A Prelude to Action, Weston MA: Pittiglio, Rabin, Todd \& MacGrath, 1995.

[8] P. Suomala and L. Jokioinen, "The patterns of success in product development: a case study," European Journal of Innovation Management, vol. 6, no. 4, pp. 213-227, 2003.

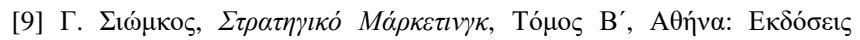

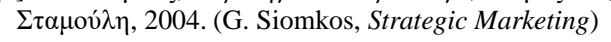

[10] H. Bergstein and H. Estelami, "A survey of emerging technologies for pricing new-to-world products," Journal of Product \& Brand Management, vol. 11, no. 5, pp. 303-318, 2002.

[11] K. B. Lee and V. Wong, "New product development proficiency and multi-country product rollout timeliness," International Marketing Review, vol. 27, no. 1, pp. 28-54, 2010.

[12] R. Panizzolo, S. Biazzo, and P. Garengo, "New product development assessment: towards a normative-contingent audit," Benchmarking: An International Journal, vol. 17, no. 2, pp. 173-194, 2010.

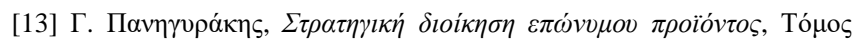

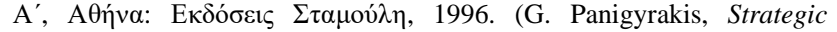
management of branded products)

[14] N. K. Denzin and Y. S. Lincoln, Handbook of qualitative research, 2nd ed. Thousand Oaks, CA: Sage Publications, 2000, p. 63.

[15] C. McDaniel and R. Gates, Marketing research essentials, South West Publishing, 1995, p. 389.

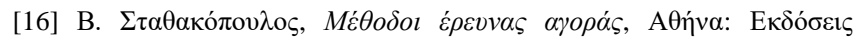

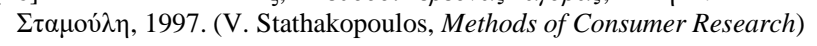

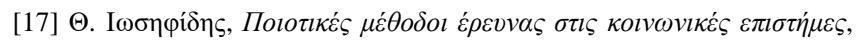

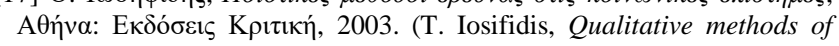
research in social sciences)

Ioanna Dimitrakaki was born in Thessaloniki, Greece, on December 11, 1986. She graduated from the department of commerce and quality control of agricultural products, Western Macedonia University of Applied Sciences, Florina, Greece (School of Technology and Agronomy) in 2009. She holds a Master of Arts in Business Management with Commendation from Kingston University, UK (2011), a Master of Business Administration from Kingston University, UK (2012), and a Ph.D. in Marketing from South-West University "Neofit Rilski", Blagoevgrad, Bulgaria (2017).

She worked in Carton Industry Modern Pack S. A., Greece. She has published "The theory of leadership and the way of its application in Greek bussiness actuality", American Journal of Management Science and Engineering, vol.4, pp. 17-25, March 2019, "Strong Brand: A Requisite for the Development of Businesses", International Journal of Innovative Studies in Sciences and Engineering Technology, vol. 5, no. 9, pp. 20-27,
2019, and "The tourist marketing and analysis of tourist satisfaction", Journal Management \& Marketing of the University of Craiova, vol. 17, no. 2, pp. 54-63, 2019.

Dr. Dimitrakaki is a member of the Editorial Board in Economics in the USA Journal Management Science and Engineering for the years 2018-2020. She received a two-year scholarship from the Greek State Scholarships Foundation and an award for her student performance during the fourth year of her studies in the Department of Commerce and Quality Control of Agricultural Products in 2009. 